\title{
Mechanical Properties of Silicon Carbide Fibers by Spherical Indentation Technique
}

J.A. Bencomo-Cisneros ${ }^{1}$, S. Young Chávez ${ }^{2}$, J.E. Ledezma-Sillas ${ }^{1}$, W. Antúnez-Flores ${ }^{1}$, A. Díaz-Díaz ${ }^{1}$, J.M. Herrera-Ramírez ${ }^{1}$.

${ }^{1}$ Centro de Investigación en Materiales Avanzados (CIMAV), Laboratorio Nacional de Nanotecnología, Miguel de Cervantes No.120, 31109 Chihuahua, Chih., México.

${ }^{2}$ Universidad Autónoma de Chihuahua (UACH), Facultad de Ingeniería, Circuito No. 1, Nuevo Campus Universitario, 31125 Chihuahua, Chih., México.

It is generally well known that, the polycrystalline ceramic fibers of silicon carbide in form of continuous monofilaments have been commercially produced for over 30 years [1]. The main application of these fibers is the composite materials reinforcement, destined to be used at elevated temperatures, above $1000^{\circ} \mathrm{C}$. These fibers have many excellent properties, such as high elastic modulus, creep resistance, thermal stability and high resistance to oxidation and chemical attack. Composite materials reinforced with $\mathrm{SiC}$ fibers have excellent thermo-mechanical properties that allow several applications for advanced structures. The SiC fibers available in the market are produced by Japanese firms. The mechanical properties of continuously reinforced metal or ceramic matrix composites strongly depend on those of the fibers. It is therefore necessary to characterize the mechanical properties of the individual fibers to be able to design the proper composite materials [2].

Nanoindentation test involves the indention of a specimen by a very small load using a high precision instrument, which records the load and displacement continuously. The main aim of this work was to determine the mechanical properties of SiC fibers through spherical indentation; the experiments were carried out by nanoindentation on single monofilaments. The materials examined were Hi-Nicalon fibers, manufactured by Nippon Carbon Co., Ltd (NCK). The indentation tests were performed at room temperature on an Agilent Technologies G200 Nanoindenter, with a spherical indenter with radius of 1 $\mu \mathrm{m}$. The indenter was used to directly determine the nanomechanical properties, hardness and Young's modulus. Prior to the tests the equipment was calibrated using a standard fused silica sample, following the method described elsewhere [3]; the conditions of calibration are drawn from standard ISO 14577-3. The analysis was based on the Oliver-Pharr method, where the load-depth unloading curve is used [3].

In order to known the as-received fibers, their diameter was measured using a scanning electron microscope (SEM) JEOL JSM 7401 F. Fig. 1 shows two SEM micrographs of the Hi-Nicalon fibers. In Fig. 1a some diameter measurements on the surface of a fiber can be seen; the diameter was variable along the fiber length, as reported elsewhere [4]; the average diameter obtained was $15 \mu \mathrm{m}$. Fig. 1b presents the cross section of a fiber before being tested. An image of an indentation performed on a fiber surface, can be seen in Fig. 2a. A representative load-displacement curve is shown in Fig. 2b, as a result of an indentation test using a full load cycle. As the load is increased, the indenter sinks into the material due to both elastic and plastic deformation. When the indenter is unloaded, the material recovers by a process primarily elastic. The elastic modulus obtained from this study was $222 \mathrm{GPa}$ and the hardness was $32 \mathrm{GPa}$; the hardness is simply defined as the applied load divided by the area of the residual indentation. The microstructure of the $\mathrm{SiC} \mathrm{Hi-Nicalon} \mathrm{fibers} \mathrm{was} \mathrm{investigated} \mathrm{using} \mathrm{HRTEM} \mathrm{and} \mathrm{was}$ published in one of our previous papers [5]. 
References

[1] A.R. Bunsell, Handbook of tensile properties of textile and technical fibres, 1st ed., Woodhead Publishing Limited, Cambridge, 2009.

[2] V. Lavaste, J. Besson, A. R. Bunsell, Statistical analysis of strength distribution of alumina based single fibres accounting for fibre diameter variations. J. Mater. Sci., 30 (1995) 2042-2048.

[3] W.C. Oliver and G.M. Pharr, An improved technique for determining hardness and elastic modulus using load and displacement sensing indentation experiments. J. Mater. Res., 7 (6) (1992) 15641583.

[4] T. Morimoto and T. Ogasawara, Potential strength of Nicalon ${ }^{\mathrm{TM}}$, Hi Nicalon ${ }^{\mathrm{TM}}$, and Hi Nicalon Type $S^{\text {TM }}$ monofilaments of variable diameters. Composites Part A: 37 (3) (2006) 405-412.

[5] I. Luján-Regalado et al., Structural and Mechanical Characterization of Hi-Nicalon Fibers. Microsc. Microanal. 18 (Suppl 2) (2012) 788-789.
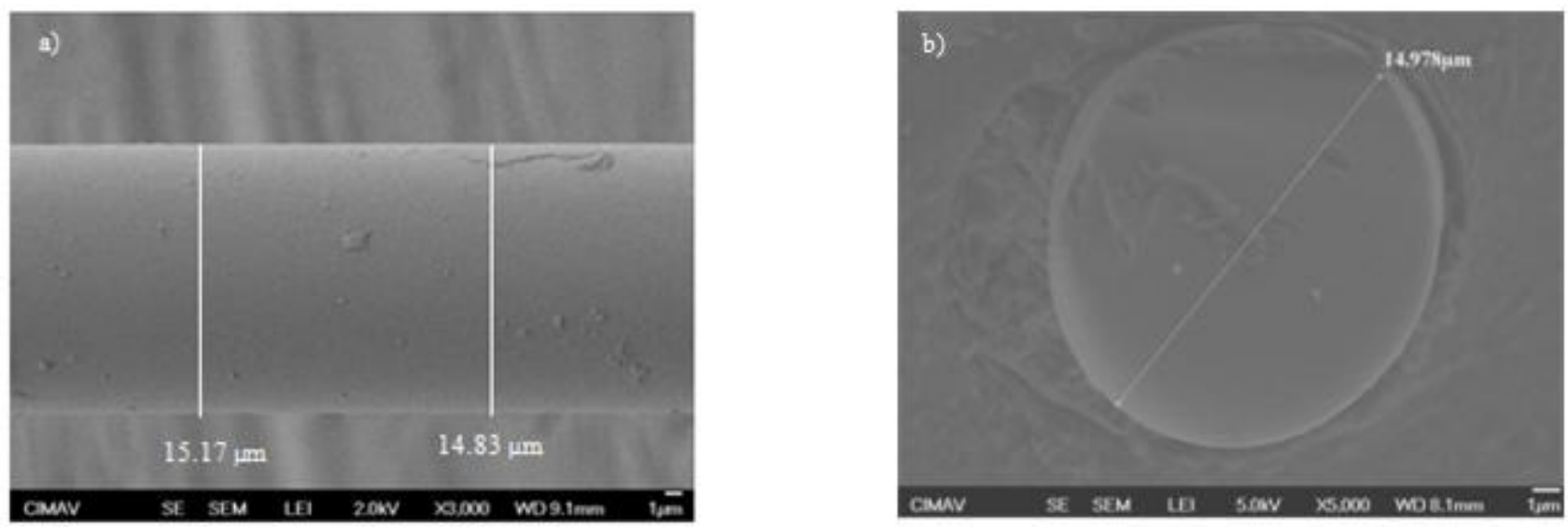

Figure 1. SEM micrographs showing a) the as-received fiber and the diameter measurement on the fiber surface, and b) cross section of a fiber before testing, showing the diameter measurement.
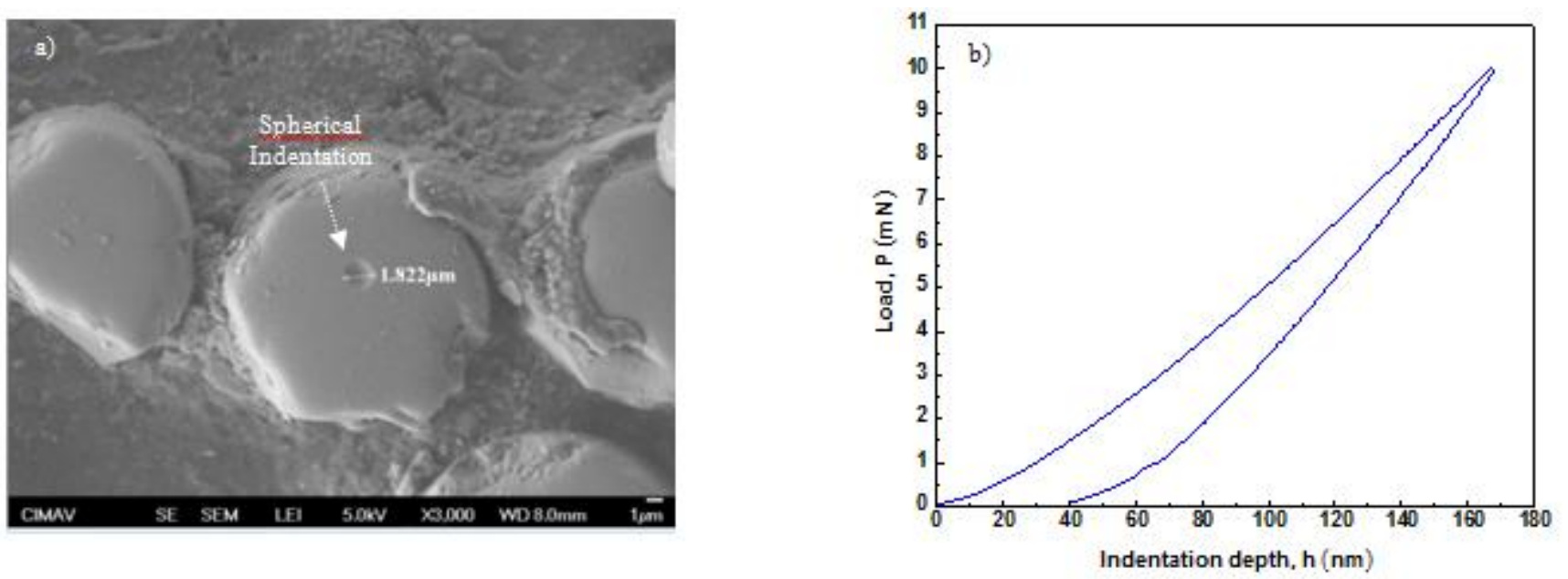

Figure 2. a) SEM micrograph showing an indentation on a fiber, and b) load-displacement curve from the nanoindentation test. 